\title{
The Development of the Physical Activity and Social Support Scale
}

\author{
Natalie M. Golaszewski and John B. Bartholomew \\ The University of Texas at Austin
}

\begin{abstract}
Research suggests 5 forms of social support: companionship, emotional, informational, instrumental, and validation. Despite this, existing measures of social support for physical activity are limited to emotional, companionship, and instrumental support. The purpose was to develop the Physical Activity and Social Support Scale (PASSS) with subscales that reflected all 5 forms. Participants $(N=506$, mean age $=34.3 \mathrm{yr})$ who were active at least twice per week completed a 235 -item questionnaire assessing physical activity behaviors, social support for physical activity, general social support, and other psychosocial questions. Exploratory and confirmatory factor analyses were used to develop and validate the PASSS. Exploratory factor analysis supported a 5-factor, 20-item model, $\chi^{2}(100)=146.22, p<.05$, root mean square error of approximation $=.05$. Confirmatory factor analysis indicated good fit, Satorra-Bentler $\chi^{2}(143)=199.57, p<.001$, root mean square error of approximation $=.04$, comparative-fit index $=.97$, standardized root mean square residual $=.06$. Findings support the PASSS to measure all 5 forms for physical activity.
\end{abstract}

Keywords: adults, measurement, physically active, psychometrics, social network

Physical activity leads to psychological and physiological benefits such as improvements in mental and cardiometabolic health (Centers for Disease Control and Prevention, 2018). According to the 2018 Physical Activity Guidelines for Americans, being physically active for $150-300 \mathrm{~min}$ at a moderate intensity or 500-1,000 metabolic equivalent (MET)-minutes per week increases the likelihood of attaining these benefits (2018 Physical Activity Guidelines Advisory Committee, 2018). However, only $43.5 \%$ of the U.S. population (aged 18-60 years) engage in the recommended amount of physical activity (HealthyPeople 2020, 2014). As a result, there has been an extensive history of research into social-psychological processes that might be related to physical activity. One of the more researched areas is social support (Courneya, Plotnikoff, Hotz, \& Birkett, 2000; Sallis, Hovell, Hofstetter, \& Barrington, 1992; Trost, Owen, Bauman, Sallis, \& Brown, 2002). However, there is a gap between how social support is conceptualized in physical activity research compared with other broader areas of health, especially in regard to coping with stress.

According to Cohen, Underwood, and Gottlieb (2000b), social support is defined as the perceived availability of social resources as well as the support that is provided in the context of support groups and informal social relationships. Within the buffering hypothesis, social support has been shown to critically reduce or ameliorate the negative experiences of an individual's stressful event (Cohen \& McKay, 1984; Cohen \& Wills, 1985). There are two explanations for why social support serves as a buffer or protective factor. First, social support bolsters coping skills and developing solutions, lowering the appraisal of the stressful situation (Thoits, 1986). Second, social support reduces or alters the affective, physiological, or maladaptive response to the stressful situation (Cohen et al., 2000 b), thereby allowing enhanced coping with stress. As such, one would expect social support to be a key contributor to physical activity behaviors. In fact, there is extensive research indicating a

The authors are with the Dept. of Kinesiology and Health Education, University of Texas at Austin, Austin, TX. Golaszewski (ngolaszewski@utexas.edu) is corresponding author. positive relationship between social support, physical attendance, and adherence in the exercise setting (Cousins, 1995; Courneya \& McAuley, 1995; Duncan \& McAuley, 1993; Duncan \& Stoolmiller, 1993; Oka, King, \& Young, 1995; Oman \& Duncan, 1995). Furthermore, social support is a predictor of intention of physical activity (Courneya et al., 2000), and supportive spouses, friends, and/or family increase physical activity behaviors (Eyler et al., 1999; Sallis et al., 1992). In fact, over the past 25 years, a number of systematic reviews of social support for physical activity among adults have overwhelmingly supported the importance of social support for physical activity behaviors (Bauman et al., 2012; Carron, Hausenblas, \& Mack, 1996; McNeill, Kreuter, \& Subramanian, 2006; Scarapicchia, Amireault, Faulkner, \& Sabiston, 2017; Sherwood \& Jeffery, 2000; Tay, Tan, Diener, \& Gonzalez, 2013; Trost et al., 2002; Wendel-Vos, Droomers, Kremers, Brug, \& van Lenthe, 2007). Despite the positive influence social support has on physical activity, the existing research for social support and physical activity is lacking an assessment of all functional forms of social support as laid out by Cohen et al. Furthermore, the sources of social support have been limited to family, friends, and/or experts.

Functional social support refers to the available support an individual perceives they have when they need to cope with acute or chronic stresses (Cohen, Underwood, \& Gottlieb, 2000a). There are five well-established forms of functional social supportemotional, companionship, instrumental, informational, and validation (Argyle, 1992; Berkman \& Glass, 2000; Cohen et al., 2000b; House, 1981). Emotional support is defined as advice, positive messages, encouragement, or acceptance during times of struggle. Companionship support is a sense of belonging, being part of a community, having someone to rely on, or having someone to do an activity with. Instrumental support is anything that allows for an individual to carry out the behavior such as having the appropriate gear, someone to take care of household tasks in their absence, or the financial support to engage in the behavior. Informational support is easily accessible instructions or information for the behavior or behavior change, or how to improve the behavior. Validation support is where individuals seek out 
others for social comparison, information on normative behaviors and feelings, or relative status in a group. More recently, there have been two systematic reviews that focus on multiple forms of social support for physical activity (Scarapicchia et al., 2017; Tay et al., 2013). While these forms of functional social support have been broadly applied in other health domains, only three forms are consistently measured in the physical activity literature: companionship, emotional, and instrumental (Scarapicchia et al., 2017; Tay et al., 2013). Thus, the extant literature ignores informational and validation support for physical activity. Moreover, much of the existing physical activity-specific literature blends companionship, emotional, and instrumental support into an overall indicator of social support. This prevents the ability to partition their influence on physical activity behaviors. Thus, we are unable to understand how patterns of physical activity behavior might vary in relation to the different forms of social support over time. This undermines the ability to develop targeted and dynamic interventions to increase social support for physical activity.

The failure to consider the individual contributions of the multiple forms of social support likely arise from the lack of a validated measure to assess these as distinct subscales. Four validated social support for physical activity scales for adults are currently used in the physical activity literature: (a) Sallis, Grossman, Pinski, Patterson, and Nader's (1987) Social Support and Exercise Survey; (b) Chogahara's (1999) Social Influence Scale; (c) Cutrona and Russell's (1987) Social Provisions Scale adapted to physical activity by Duncan and McAuley (1993); and (d) Gillett's (1988) Feelings about Exercise Scale. Of these, the Social Support and Exercise Survey (Sallis et al., 1987) has been the most widely used (Scarapicchia et al., 2017). This scale is designed to ask from whom do you feel support — choosing from family or friends - and who helps you carry out the activities. The resulting summed score ignores the multiple forms of social support and misses potential support from coworkers, medical professionals, other experts, or anyone beyond friends and family. The Social Influence Scale (Chogahara, 1999) has a similar design, though items are assessed from a broader group of individuals (i.e., family, friends, or experts). The Feelings about Exercise Scale (Gillett, 1988) measures social support through peer-group factors and is therefore limited to companionship support. The Social Provisions Scale (Cutrona \& Russell, 1987) was originally designed to assess a broad range of psychosocial factors: attachment, social integration, reassurance of worth, alliance, nurturance, and guidance. While it was adapted to measure social support for exercise (Cutrona \& Russell, 1987; Duncan \& McAuley, 1993; Weiss, 1974), it is unclear whether the subscales map onto any of the five forms of functional social support.

While these scales provide a valid assessment of some aspect of social support, none reflect the full breadth of forms of functional social support that have been used in Cohen's model (2000b) as it is applied to buffering stress. Moreover, because these do not include specific subscales for each form of social support, it is impossible to discern the relative contribution of each. This undermines the effort to tailor intervention design (e.g., comparing the impact of programs designed to increase companionship vs. those designed to increase validation) and whether the impact might vary across different subgroups. It is clear that there is a gap in our understanding of how different forms of social support might influence physical activity. Thus, there is a need for an updated, multidimensional measure to assess forms of social support for physical activity, with distinct subscales to assess each form of social support. The purpose of this research was to develop and validate a social support for physical activity scale, the Physical Activity and Social Support Scale (PASSS), with distinct subscales that reflect each of the five, hypothesized forms of social support-companionship, emotional, instrumental, informational, and validation. The results add a measurement tool that encompasses five forms of social support for physical activity that will aid in the creation of informative and comprehensive interventions to increase adherence to physical activity through a targeted change in social support.

\section{Methods}

\section{Scale Development}

During the initial stage of this project, theory-based general social support scales (e.g., Cohen, Mermelstein, Kamarck, \& Hoberman, 1985; Cohen et al., 2000a; Gottlieb \& Bergen, 2010; Sherbourne \& Stewart, 1991) as well as existing social support for physical activity scales for adults were reviewed (e.g., Barber, 2012; Cutrona \& Russell, 1987; Gillett, 1988; Sallis, Calfas, Alcaraz, Gehrman, \& Johnson, 1999; Scarapicchia et al., 2017). The most commonly used forms of social support were companionship, emotional, instrumental, informational, and validation (Cohen et al., 2000a). From there, items were developed that reflected the definitions of the five forms of social support, existing social support for physical activity scales, and the current climate of physical activity and exercise. Sixty items were written based in the five forms of social support-14 items for companionship support, 10 items for emotional support, 11 items for informational support, 11 items for instrumental support, and 14 items for validation. Three expert reviewers, each from the disciplines of health psychology, social psychology, and kinesiology, reviewed the final 60 items for readability, appropriateness, and comprehension as well as provided feedback on the items to establish content validity.

\section{Scale Scoring}

The items were anchored on a 7-point Likert scale from 1 (not at all true) to 7 (very true), along with a "not applicable" option (n/a), which results in a zero on the Likert scale. Instead of limiting the items to a single individual, or friends and family, the instructions ask participants to consider all the people or sources an individual may perceive to provide social support within their social network. This allows for a broader sense of social support than what is captured in existing scales.

\section{Focus-Group Methods}

\section{Participants}

Adults (aged 18-75 years) who engage in physical activity at least two times per week were recruited to participate in three focus groups to discuss the initial items in the PASSS. Participants $\left(N=14 ;\right.$ male $=5 ; M_{\text {age }}=32$ years $)$ were recruited from various locations including: community bulletin boards, social media platforms, campus bulletin boards, community Listservs, and exercise centers. The University of Texas at Austin institutional review board approved this study.

\section{Procedures}

Item Generation. At the beginning of each focus group, the study and tasks required by the participants were described, and consent 
was obtained. They were then divided into smaller groups and asked to complete a Q-sort task (Stephenson, 1953) where they reviewed the PASSS items and grouped them based on how items related to each other. The rationale for using the Q-sort methodology was to explore the initial construct validity and reliability of the items by assessing the percent agreement between the way the items were constructed based on the forms of social support, and how the participants grouped the items (Nahm, Rao, Solis-Galvan, \& Ragu-Nathan, 2002). Thus, the findings from the Q-sort were to identify any items that were clear misfits prior to proceeding with the exploratory analysis.

After the completion of this task, the groupings were recorded and saved for later analysis. Following the Q-sort, the group discussion was audio recorded, where 11 open-ended questions (e.g., Please tell me more about why you placed these items together. What did you think of the items? Are there any additional items that should be added?) were asked to explore why participants grouped items the way they did and whether additional items should be added.

Each groups' categories of items were examined for the consistency of categories as well as identifying any outlier items across all six groups of people (three groups, with two groups each). The audio recordings of the three focus groups were analyzed using an iterative approach (Corbin \& Strauss, 2007) creating themes that reflected the perceptions of the PASSS items and the process of categorizing the items. On average, the groups matched $68 \%$ of the emotional support items, $54 \%$ of the companionship items, $55 \%$ of the instrumental items, $57 \%$ of the informational items, and $51 \%$ of the validation items. From the results of the Q-sort task and discussion posttask, two items were modified for clarity. In addition, based on the qualitative analysis of the discussions following the Q-sort task, five items were created to capture participants' experiences with online communities, social media, and instrumental support. A finalized 65-item scale was developed. This scale was then used in the exploratory factor analysis (EFA).

Factor Analyses. The list of 65 items was analyzed via an EFA to select a smaller set of items and fit a factor structure to the data. This was followed by a confirmatory factor analysis (CFA) and initial test of convergent and discriminant validity on the measurement model identified in the EFA.

\section{Participants}

Adults (aged 18-75 years) who engaged in physical activity at least two times per week were recruited via social media advertisements; online activity groups and forums related to physical activity; exercise clubs (running, climbing, rowing); walking programs; and regular gyms (i.e., Gold's, Planet Fitness, 24 Hour Fitness, YMCA) to complete a questionnaire that assessed demographics, physical activity behaviors, and other psychosocial determinants of physical activity. They were also recruited from various locations including: online community bulletin boards, online events calendar on the University of Texas at Austin's campus, neighborhood Listservs, and two upper division undergraduate courses. At the end of the online questionnaire, participants were asked if they would be interested in participating in a follow-up, online survey. Participants had the option to enter a gift card raffle. This resulted in a sample of 546 participants. Of these, $50 \%$ of the sample $(N=273)$ were randomly sampled for the EFA. The remaining participants were used in the CFA. The institutional review board the University of Texas at Austin approved this study.

\section{Measures}

Demographics. Participant-level questions such as gender, race, ethnicity, state they currently live in, marital status, education level, age, preferred type of exercise, type of gym they belonged to, if they participated in exercise groups, if they have been engaging in physical activity regularly for the past 6 months, and intended to become more physically active in the next 6 months were assessed through separate questions. One item assessed current overall level of stress where participants could respond on a 10-point Likert scale from 1 (not at all stressed), 5 (moderately stressed), or 10 (very stressed).

PASSS. Participants responded to 65 items on a 7-point Likert scale to the extent that each of the items relate to the activity that they closely relate to 1 (never), 4 (sometimes), 7 (always), or 0 (not applicable). This scale is based in five forms of social supportcompanionship, emotional, instrumental, informational, and validation. For example, an item based in companionship support asked "I feel a sense of belonging to a group of people who do the activity/activity I do." This scale has yet to be used in research. Thus, the purpose was to develop and validate this scale. See Appendix for the final version of the scale.

Social Provisions for Exercise Scale. This 24-item scale is designed to assess the extent social support for physical activity items are related to individuals in their social network (friends, family members, coworkers, community members; Cutrona \& Russell, 1987; adapted to exercise by Duncan \& McAuley, 1993). Participants responded to items such as "There are people who admire my talents and abilities" on a 4-point Likert scale from 1 (strongly disagree), 2 (disagree), 3 (agree), or 4 (strongly agree). An average social support score was calculated, where higher scores reflected greater social support for exercise. This survey has been validated and used among adults with alpha levels between .66 and .92 (Courneya et al., 2000; Duncan \& McAuley, 1993). The alpha level for this sample was .91 .

Social Support and Exercise Survey. This 13-item scale is designed to measure whether family members or friends influence physical activity and exercise behaviors (Sallis et al., 1987). Participants responded on a 5-point Likert scale how often (1, none to 5, very often) in the past 3 months family or friends have said or done what is described in the items (e.g., Offered to exercise with me.). An average social support score was calculated for friends, family, and combined friends and family, where higher scores indicate greater social support for physical activity and exercise. Cronbach alpha for this scale was .90 (family members = .89 ; friends $=.90$ ).

Interpersonal Support Evaluation List-12. This 12-item scale is designed to measure overall perceived social support among adults in the general population (Cohen et al., 1985). This scale is designed to measure emotional, instrumental, companionship, and validation social support constructs. Participants responded to the statements (e.g., If I were sick, I could easily find someone to help me with my daily chores.) each of which may or may not be true about themselves, 1 (definitely false) to 4 (definitely true). An average social support score was calculated, where higher scores reflected greater social support. The Cronbach alpha for this sample was .65 .

Exercise Dependence Scale. There were 21 items in this scale that assessed maladaptive patterns of exercise on a 7-point Likert scale from 1 (never) to 6 (always; Hausenblas \& Downs, 2002). 
Participants responded to items such as, "I exercise when injured." An average exercise dependence score was calculated. Higher scores on these items reflected higher exercise dependence. The Cronbach alpha for this scale was .89.

Physical Activity Enjoyment Scale. This 18-item scale assessed how participants felt at the moment about the physical activity that they have been engaging in on a 7-point Likert scale (e.g., 1, I enjoy it to 7, I hate it; 1, I feel bored to 7, Ifeel interested; Kendzierski \& DeCarlo, 1991). An average physical activity enjoyment score was calculated, where higher scores indicated greater physical activity enjoyment. The alpha level for this sample was .96 .

Exercise Identity Scale. Participants answered nine items assessing the level of perceived exercise identity (Anderson \& Cychosz, 1994). Participants responded to items such as "I consider myself an exerciser" on a 7-point Likert scale ranging from 1 (strongly disagree) to 7 (strongly agree). This scale has been validated among an adult population (Anderson, Cychosz, \& Franke, 2001). An average exercise identity score was calculated. Higher scores reflected stronger exercise identity. The alpha level for this sample was 95 .

Group Identity Scale. Participants answered 12 items to assess level of group exercise identity specific to the physical activity or exercises they participate in (Cameron, 2004). An example item asks "In general, being part of this group is important to my selfimage." On a 7-point Likert scale ranging from 1 (strongly disagree) to 7 (strongly agree), they answered questions about perceived importance of group to self-definition and cognitive centrality of the group that pertain to the physical activity that they engage in. An average group exercise identity score was calculated, where higher scores indicated stronger group exercise identity. The Cronbach alpha was .81 for this sample.

Ten-Item Personality Scale. The Ten-Item Personality Scale assesses the Big-Five personality dimensions such as extraversion (e.g., extraverted, enthusiastic); agreeableness (e.g., sympathetic, warm); conscientiousness (e.g., dependable, self-disciplined); emotional stability (e.g., calm, emotionally stable); and openness to experiences (e.g., open to new experiences, complex) through 10 items (Gosling, Rentfrow, \& Swann, 2003). Responses to these items include 1 (disagree strongly) to 7 (agree strongly). An average of items that reflect the personality dimension was calculated. This scale has been validated with an adult population and has good internal reliability: .58-.77 (Ehrhart et al., 2009; Furnham, 2008). The reliability of this scale for this sample was an alpha level of .56.

International Physical Activity Questionnaire. The International Physical Activity Questionnaire is a physical activity and sedentary behavior surveillance scale (Craig et al., 2003). Participants were asked about time spent being physical active in the last 7 days such as housework, transportation, and leisure time. They were also asked on how many days they engaged in vigorous activity and the average amount of time (in hours) spent doing it/them. Participants responded to moderate activity (not including walking), walked for at least $10 \mathrm{~min}$ at a time, time spent sitting on a nonworkday, and time spent sitting on a workday. From this information, METminutes per week were calculated by the following formula: MET value for level of intensity $\times$ minutes spent in the activity $\times$ number of days. Then a total MET value for each participant was calculated by summing the vigorous, moderate, and walking MET-minutes per week. For sitting behaviors, the following formula was used to calculate MET-minutes per week: minutes sitting $\times$ number of days. The number of hours were summed for time spent sitting on a nonworkday and a workday for total hours sitting per week. This scale was established with an adult population and has shown to have average validity (Craig et al., 2003).

Self-Report Modifiable Activity Questionnaire. The self-report Modifiable Activity Questionnaire (S-MAQ) is a physical activity surveillance scale that assesses whether an individual participates in a certain activity, the number of months they participate, the number of times within that month, and the number of minutes they participate (adapted from Kriska et al., 1990). There were 44 activities listed in the S-MAQ. From this information, MET-minutes per week were calculated for each activity using the following formula: MET-minutes per week $=($ MET value for the specific activity $\times$ no. of months $\times$ no. of times $\times$ no. of minutes per time)/ (60/52). Then a total MET value for each participant was calculated by summing all activities MET-minutes per week. Versions of this scale have been used with adult populations (Durand et al., 2016; Gabriel, McClain, Schmid, Storti, \& Ainsworth, 2011; Knell et al., 2017; Momenan et al., 2012).

\section{Analyses}

Preliminary analyses included histograms, skewness and kurtosis, and Mahalanobis distance were conducted on the responses to the initial pool of 65 items for the PASSS to identify outlying values and participants. The EFA was used to determine the number of factors, to identify patterns of item loadings on each factor, and to select items within each factor to be tested in the proposed CFA. The Kaiser-Meyer-Olkin and Bartlett's test of sphericity were examined to determine whether the sample size was sufficient to carry out the EFA. A Kaiser-Meyer-Olkin > .60 and a Bartlett's test of $p<.05$ indicated appropriate sample size. All analyses were conducted using SPSS (version 25; IBM Corp., Armonk, NY; Statistical Package for the Social Sciences, 2017).

\section{Factor-Extraction Methods}

Once the reduced correlation matrix for the EFA sample was obtained, parallel analysis was conducted, examination of the scree plot, and root mean squared estimate analysis (root mean square error of approximation, RMSEA) for models were conducted. The RMSEA was used as an indicator of model fit based on the number of factors for a given model (Fabrigar \& Wegener, 2011).

\section{Item-Retention Methods}

After the appropriate number of factors were determined, dimension reduction analysis in SPSS (version 25) was conducted using maximum likelihood with a Promax rotation, which is commonly used for EFA (Fabrigar \& Wegener, 2011; Pituch \& Stevens, 2015). A Promax rotation is an oblique rotation such that it allows for the latent constructs to correlate. Therefore, it was decided a priori that a Promax rotation would be used as any latent social support constructs should correlate, but also be separate factors.

After the EFA was conducted, items with communalities equal to or greater than .30 were retained. The second method for item retention was to examine the pattern matrix. The pattern matrix can be interpreted as the association between the item and their respective factor. Items that had a correlation greater than .40 with their respective factors were retained. Items that cross-loaded on factors were removed. To reach a final model, the variance of the model explained at least $50 \%$, three items correlated with each factor, and the latent factors and items made theoretical sense 
(Fabrigar \& Wegener, 2011; Pituch \& Stevens, 2015). Standardized loadings were used to interpret all findings.

\section{Results}

\section{Preliminary Analysis Results}

Histograms, skewness, and kurtosis of each of the PASSS items were inspected for normality. Eight participants were removed according to their Mahalanobis distance scores as they were less than .001 indicating that they were outside the range of the central point of the other participants (Pituch \& Stevens, 2015). Furthermore, we inspected the data for participants who responded with the same number for all the PASSS items, completed the questionnaire in less than $10 \mathrm{~min}$, or reported dubious answers to the open-ended questions, suggesting a possible lack of seriousness or attentiveness. No participants were removed from the EFA sample based on these criteria. The final sample resulted in 265 participants $\left(M_{\mathrm{age}}=34.3\right.$ years, $\left.S D=12.8\right)$. Participants were $89 \%$ non-Hispanic, $84 \%$ white, and $70 \%$ female. Participants' level of education included $9 \%$ doctoral degree, $30 \%$ master's, $36 \%$ bachelor's, $6 \%$ associate's, $2 \%$ professional, $2 \%$ trade/tech/vocational training, and $12 \%$ high school or equivalent. Reported marital status included $43 \%$ were single, $49 \%$ married or domestic partnership, $6 \%$ divorced, and $1 \%$ widowed. Overall, the stress level $(M=5.16, S D=$ 1.86) indicated a moderately stressed group. For the past 6 months,
$89 \%$ of the sample reported being physically active, and $73 \%$ intended to become more physically active in the next 6 months. About $37 \%$ belonged to an exercise group and $29 \%$ belonged to a specialized group (e.g., CrossFit, Orange Theory). According to the S-MAQ, on average this sample engaged in 2,157.82 ( $S D=$ 1,749.09) MET-min/week, which is above the physical activity guidelines of $600 \mathrm{MET}-\mathrm{min} /$ week. The Kaiser-Meyer-Olkin $=.90$ and Bartlett's test of sphericity $p<.001$ indicated that there was an appropriate number of participants in the sample to run the EFA.

\section{EFA Results}

Results from the parallel analysis showed a five-factor model. The point of inflection on the scree plot indicated a five-factor model. The RMSEA of each model showed that a five-factor model $(\mathrm{RMSEA}=.05)$ was superior than a six-factor model $(\mathrm{RMSEA}=$ .06). We then conducted the maximum likelihood model with a Promax rotation. Using the item-retention methods, the model was reduced to four items for each of the five factors (see Table 1 for pattern matrix). The model explained $55.8 \%$ of the variance. To determine the social support construct of each latent factor, items in the pattern matrix that loaded on each factor were examined and compared with their hypothesized loading. For example, emotional support is defined as advice, positive messages, encouragement, or acceptance during times of struggle. Items such as "I have someone who can provide reassurance in the activity/activities" and "There

Table 1 Pattern Matrix for the Physical Activity and Social Support Scale $(N=265)$

\begin{tabular}{|c|c|c|c|c|c|}
\hline & \multicolumn{5}{|c|}{ Factor } \\
\hline & 1 & 2 & 3 & 4 & 5 \\
\hline I have someone who can provide reassurance in the activity/activities. & 1.02 & .00 & -.09 & -.05 & -.04 \\
\hline There is someone that provides me with positive feedback in the activity/activities. & .93 & .12 & -.08 & -.08 & .01 \\
\hline There is someone who understands my problems/worries about the activity/activities. & .59 & -.10 & .18 & .04 & .08 \\
\hline I have someone with whom I can relate to in the activity/activities. & .56 & -.08 & .12 & .25 & .06 \\
\hline I set expectations based on the performance of others in the activity/activities. & .02 & .93 & -.07 & -.01 & -.07 \\
\hline $\begin{array}{l}\text { I want to know competition results (i.e., race results), times, duration, weights, or } \\
\text { actions of others in the activity/activities. }\end{array}$ & -.07 & .64 & .00 & .19 & .06 \\
\hline I compare myself to others in the activity/activities. & .12 & .62 & .11 & -.06 & .02 \\
\hline $\begin{array}{l}\text { I use social media to find other people's performance in the activity/activities to } \\
\text { compare to my own. }\end{array}$ & -.06 & .44 & .28 & -.11 & .09 \\
\hline I read articles about the activity/activities. & -.06 & .17 & .75 & -.14 & .09 \\
\hline I seek out information from others to get better at the activity/activities. & .14 & -.08 & .74 & .05 & -.05 \\
\hline I talk to people for assistance or to improve technique in the activity/activities. & .10 & .03 & .65 & .09 & .05 \\
\hline I attend clinics, classes, and workshops to learn about the activity/activities & -.11 & -.02 & .62 & .13 & .03 \\
\hline I am a part of a core group of people who do the activity/activities. & .12 & .03 & -.08 & .81 & .00 \\
\hline $\begin{array}{l}\text { When not engaging in the activity/activities, I still spend time with people that I met } \\
\text { while in the activity/activities. }\end{array}$ & .00 & -.02 & -.02 & .69 & -.08 \\
\hline I feel a sense of belonging to a group that also does the activity/activities I do. & .04 & .20 & .03 & .69 & -.13 \\
\hline I can find someone to do the activity/activities with, even outside of my friends. & -.13 & -.01 & .12 & .65 & .11 \\
\hline I can get help traveling if needed to perform the activity/activities. & -.03 & .12 & -.08 & .05 & .71 \\
\hline $\begin{array}{l}\text { I have someone that could loan or give me something to help carry out the activity/ } \\
\text { activities I do. }\end{array}$ & .01 & .03 & -.03 & .10 & .67 \\
\hline $\begin{array}{l}\text { I have someone who would watch my child(ren) or pets if needed for me to engage in } \\
\text { the activity/activities. }\end{array}$ & .04 & -.12 & -.09 & -.11 & .61 \\
\hline $\begin{array}{l}\text { I can find someone to help on short notice so that I can engage in the activity/ } \\
\text { activities. }\end{array}$ & .02 & .05 & .09 & -.10 & .58 \\
\hline
\end{tabular}

Note. Bold values denote items that had a correlation greater than .40 with their respective factors and were retained. 
is someone that provides me with positive feedback in the activity/ activities" loaded together on the same factor. Therefore, Factor 1 was labeled as emotional support since four emotional support items were highly correlated with this factor. This was the same for Factor 2, which is validation support; Factor 3 is informational support; Factor 4 is companionship support; and Factor 5 is validation support. This was the same scenario for each of the five factors. The communalities ranged from .30 to .86 indicating that the items fit well together among the extracted number of factors. The pattern coefficients ranged from 1.02 to .44 showing that there are strong associations between items and their respective factors. It is important to note that the pattern coefficients are not bound to the standard correlations range of -1 to 1 ; therefore, it is acceptable to have coefficients above 1 (Fabrigar \& Wegener, 2011). The model showed good fit indicated with a significant chisquare, $\chi^{2}(100)=146.22, p<.01$. The Cronbach alpha for the finalized five-factor, 20-item scale was .90. The alpha levels for the subscales were companionship .81, emotional .89, informational .81, instrumental .71, and validation .79. A total mean score can be calculated that assesses the degree of perceived social support for physical activity. In addition, a mean score for each form of social support (companionship, emotional, instrumental, informational, and validation) can be calculated. The higher the mean for each form, the greater the perceived social support.

\section{CFA}

The EFA indicated a five-factor, 20-item multidimensional PASSS based in the five forms of functional social support: companionship, emotional, informational, instrumental, and validation. However, it is likely that the EFA reflected random error in the solution. As such, it was important to further test structure through CFA. Prior to conducting the CFA, the number of observed variables and the estimated parameters were calculated and compared to determine whether the model was under-, just-, or overidentified.

\section{CFA Methods}

In order to have enough power for the models, Kenny (2015) supports the use of 200 participants. Muthén and Muthén (2002) shown through simulation studies that a sample greater than 150 is sufficient to conduct a CFA. Using these guidelines, we decided a priori to recruit 250 participants to have sufficient power. The final sample for the CFA $(N=273)$ had enough power for testing and interpreting the findings from the CFA. Preliminary analyses were conducted in SPSS (version 25; Statistical Package for the Social Sciences, 2017). CFA was conducted in Mplus (Muthén \& Muthén, 2008). Standardized loadings were reported and used for interpretation.

Model fit is the ability to replicate the correlation or covariance matrix of items and factors in another sample (Byrne, 2011). The five factors from the EFA are considered latent or exogenous factors, and the items are considered endogenous factors with error variances. The factor variances were set to 1 such that they were considered standardized. Model fit indices were assessed using Satorra-Bentler (S-B) chi-square (Satorra \& Bentler, 1988) and robust standard errors, comparative-fit index (CFI; Bentler, 1990) and Tucker-Lewis index (TLI; Tucker \& Lewis, 1973), standardized root mean square residual (SRMR; Bentler, 1990), and the RMSEA (Steiger, 1990). The S-B chi-square has been shown to be a robust maximum likelihood mean-adjusted test that corrects for nonnormal data (Satorra \& Bentler, 1988). The CFI and TLI range from 0 and 1 , where 1 is a perfect model fit and values greater than .95 indicate a good model fit (Hu \& Bentler, 1999). SRMR and RMSEA values that are less than .08 indicate adequate model fit, values less than .05 correspond to excellent model fit, and .00 represent exact model fit (Browne \& Cudeck, 1992; Hu \& Bentler, 1999; Loehlin, 1998). We examined all of the model fit indices as research cautions the interpretation of solely the chisquare statistic as it is sensitive to sample size, size of correlations, and the assumption that the sample covariance matrix equals the restricted covariance matrix (Brown, 2006; Jöreskog \& Sörbom, 1993; MacCallum, Browne, \& Sugawara, 1996). Finally, in case of poor model fit, modification indices were examined and added in order to improve the fit as long as these modifications to the model made sense theoretically.

\section{Construct-Validity Methods}

Convergent and discriminant validity were tested to determine the correlations between existing social support for physical activity scales Social Support and Exercise Survey, the Social Provisions for Exercise Scale, and a general social support scale the Interpersonal Support Evaluation List-12, and the PASSS. The purpose was to assess social support and forms of social support across scales. We hypothesized there to be positive, moderate correlations among similar social support constructs across the scales. To better understand the profiles of individuals who report greater social support for physical activity, bivariate correlations were conducted between the PASSS and the Physical Activity Enjoyment Scale, Exercise Identity Scale, Group Exercise Identity Scale, Exercise Dependence Scale, Ten-Item Personality Scale, self-report Modifiable Activity Questionnaire, and International Physical Activity Questionnaire. The entire sample was used to examine construct validity (see Table 2 for convergent and discriminant validity demographics).

The correlations between the PASSS and other psychosocial determinants of physical activity were examined based on the existing literature and to provide direction for future research. Social support and physical activity enjoyment have been shown to be positive correlates of physical activity (Trost et al., 2002). It was hypothesized that social support for physical activity and physical activity enjoyment would be positively correlated. Personality was measured as we hypothesized that those who are more extroverted may be involved in more socially based physical activities (e.g., group-based physical activity), thus having increased levels of social support based on a previous systematic review (Rhodes \& Smith, 2006). Social support helps to create and sustain identities by providing a way to make sense of an individual's self and their environment (Stryker, 1980). Therefore, various forms of social support for physical activity may play an important role in exercise identity (Stryker, 1980). Group exercise identity was of particular interest as many forms of physical activity are done in group settings, and individuals may adopt an identity of a particular exercise group (Terry \& Hogg, 1996; White, Terry, \& Hogg, 1994). It is important to note that exercise identity and group exercise identity are positively correlated but are distinct constructs (Strachan, Shields, Glassford, \& Beatty, 2012).

\section{Test-Retest Reliability Methods}

To test the stability and reliability of the PASSS, a subsample of participants $(n=150)$ who indicated that they would participate in future studies were contacted to participate in a follow-up, online survey that included only the PASSS items. Correlation analyses and intraclass correlation coefficient (ICC) analyses were conducted between the first time they completed the PASSS, Time 1, with 
Table 2 Demographic Information for Convergent and Discriminant Validity $(N=506)$

\begin{tabular}{|c|c|c|c|}
\hline & Percent & $M(S D)$ & Scale range \\
\hline \multicolumn{4}{|l|}{ Race/ethnicity } \\
\hline White & 82 & - & - \\
\hline Non-White & 18 & - & - \\
\hline Hispanic & 13 & - & - \\
\hline Male & 29 & - & - \\
\hline Exercise group & 36 & - & - \\
\hline Specialized gym & 45 & - & - \\
\hline Married & 46.2 & - & - \\
\hline College degree or higher & 76 & - & - \\
\hline Age & - & $34.12(13.36)$ & $18-75$ \\
\hline Stress & - & $5.22(1.91)$ & $1-10$ \\
\hline General social support & - & $3.31(.51)$ & $1-4$ \\
\hline \multicolumn{4}{|l|}{ Personality } \\
\hline Extraversion & - & $8.43(3.32)$ & $1-14$ \\
\hline Agreeableness & - & $10.38(2.35)$ & $1-14$ \\
\hline Emotional stability & - & $9.69(2.78)$ & $1-14$ \\
\hline Conscientiousness & - & $11.11(2.41)$ & $1-14$ \\
\hline Open to new experiences & - & $10.56(2.1)$ & $1-14$ \\
\hline IPAQ MVPA/week & - & $4,576.5(3,272.58)$ & - \\
\hline Moderate PA & - & $994.15(1,317.67)$ & - \\
\hline Vigorous PA & - & $2,427.14(2,591.92)$ & - \\
\hline Walking PA & - & $1,330.98(1,480.02)$ & - \\
\hline S-MAQ MVPA/week & - & $2,108.43(1,911.85)$ & - \\
\hline Sedentary/week & - & $4,193.54(2,096.17)$ & - \\
\hline PA enjoyment & - & $6.15(1.03)$ & $1-7$ \\
\hline Exercise dependence & - & $2.67(0.84)$ & $1-6$ \\
\hline Exercise identity & - & $5.05(1.55)$ & $1-7$ \\
\hline Group exercise identity & - & $3.56(0.54)$ & $1-6$ \\
\hline Social support for exercise & - & $2.88(0.67)$ & $1-5$ \\
\hline Social Provisions Scale & - & $3.5(0.42)$ & $1-4$ \\
\hline Physical Activity and Social Support Scale & - & $3.93(1.15)$ & $1-7$ \\
\hline Emotional & - & $4.94(1.59)$ & $1-7$ \\
\hline Companionship & - & $3.98(1.57)$ & $1-7$ \\
\hline Instrumental & - & $3.25(1.69)$ & $1-7$ \\
\hline Informational & - & $4.06(1.48)$ & $1-7$ \\
\hline Validation & - & $3.43(1.53)$ & $1-7$ \\
\hline
\end{tabular}

Note. $\mathrm{IPAQ}=$ International Physical Activity Questionnaire; PA = physical activity; MVPA = moderate to vigorous PA; $\mathrm{S}-\mathrm{MAQ}=$ self-report Modifiable Activity Questionnaire.

the follow-up, Time 2. Pearson correlation coefficients of 1 indicate high reliability, while 0 indicates no reliability. ICC values less than .50 were considered poor reliability, .50-.75 indicated moderate reliability, values between .70 and .90 were considered good, and .90 or greater was indicative of excellent reliability (Koo \& Li, 2016).

\section{Results}

\section{Preliminary Results}

Histograms, skewness, and kurtosis of each of the PASSS items were inspected in this half of the overall sample for normality. According to Mahalanobis distance, five participants were removed as they were less than .001 indicating that these participants were outside the range of the central point of the other participants' scores (Pituch \& Stevens, 2015). Four participants were deleted because they responded with the same number for all the PASSS items. This was again interpreted as a possible lack of seriousness or attentiveness of their data. The final sample was 262 participants $\left(M_{\text {age }}=34.09\right.$ years, $\left.S D=13.45\right)$. Participants were $83 \%$ non-Hispanic, $79 \%$ white, and $70 \%$ female. Participants' level of education included $11 \%$ doctoral degree, $27 \%$ master's, $38 \%$ bachelor's, 4\% associate's, 4\% professional, $1 \%$ trade/tech/vocational training, and $14 \%$ high school or equivalent. Reported marital status included $51 \%$ were single, $45 \%$ married or domestic partnership, 9\% divorced, and 3\% widowed. Overall, the stress 
level $(M=5.25, S D=1.98)$ indicated a moderately stressed group. For the past 6 months, $85 \%$ of the sample reported being physically active, and $75 \%$ intended to become more physically active in the next 6 months. About 37\% belonged to an exercise group, and 28\% belonged to a specialized group (e.g., CrossFit, Orange Theory). According to the S-MAQ, this sample engaged in an average of 2,084.46 $(S D=2,076.27)$ MET-min/week, which is above the physical activity guidelines of $600 \mathrm{MET}-\mathrm{min} /$ week. The Cronbach's alpha for the PASSS was .89. The alpha levels for the subscales were companionship .82, emotional .90, informational .76 , instrumental .63 , and validation .81 .

\section{CFA Results}

The initial five-factor, 20-item model had poor model fit, S-B $\chi^{2}(160)=604.09, p<.001 ;$ RMSEA $=.10,90 \%$ confidence interval $[.09, .11], p<.001 ; \mathrm{CFI}=.77, \mathrm{TLI}=.72$; SRMR $=.09$. The modification fit indices recommended correlating errors associated with a number of items to improve model fit, which is common in CFA models (Byrne, 2011). Allowing 17 correlated errors improved model fit significantly; however, the $\mathrm{S}-\mathrm{B}$ chi-square was still statistically significant, $\mathrm{S}-\mathrm{B} \chi^{2}(143)=199.57, p=.001$; RMSEA $=$ $.04,90 \%$ confidence interval $[.03, .05], p=.93 ; \mathrm{CFI}=.97, \mathrm{TLI}=.96$; $\mathrm{SRMR}=.06$. Figure 1 shows the CFA model for the CFA sample.

\section{Test-Retest Results}

Fifteen percent of the initial sample $(n=76)$ participated in the follow-up, online survey that consisted of only the PASSS items. These participants completed the online survey 1-3 months following their initial completion of the online survey. Results from the test-retest Pearson correlation for the PASSS showed high reliability $(r=.70, p<.01)$ as did three subscales: companionship $(r=.75, p<.01)$; validation $(r=.63, p<.01)$; and informational $(r=.72, p<.01)$ support showed high reliability. Emotional $(r=.53$, $p<.01)$ and instrumental $(r=.55, p<.01)$ support showed lower, yet acceptable reliability given that these constructs have a high degree of state variation (McCrae, Kurtz, Yamagata, \& Terracciano, 2011). The ICC test-retest results for the overall PASSS showed good reliability $(\mathrm{ICC}=.82)$ as did three subscales: companionship (ICC = $.85)$, validation $(\mathrm{ICC}=.78)$, and informational $(\mathrm{ICC}=.84)$. Emotional $(\mathrm{ICC}=.67)$ and instrumental $(\mathrm{ICC}=.71)$ support showed moderate reliability levels (Koo \& $\mathrm{Li}, 2016)$.

\section{Construct-Validity Results}

Other Social Support for Physical Activity Scales. The PASSS subscales were all significantly correlated with each other $(r=$ $.27-.61, p<.01$; see Table 3 ). Convergent and discriminant validity were determined through correlations between the forms of social support in the PASSS with similar social support for physical activity scales and a general social support scale (see Table 4 for results). The overall mean PASSS score significantly correlated $(r=.53, p<.001)$ with the Social Support for Exercise Survey, with the strongest correlations for between emotional support items $(r=.49, p<.001)$ and companionship items $(r=.47, p<.001)$. The Social Provisions for Exercise Scale was moderately correlated with the overall mean PASSS score $(r=.23, p<.001)$. The Social Provisions for Exercise Scale is based in the social support constructs such as guidance (advice), attachment (emotional closeness), social integration (sense of belonging), reliable alliance (assurance from others), and worth (competence). Similarities between subscales of social support constructs in the PASSS with the Social Provisions for Exercise
Scale were examined, and concluded that guidance, attachment, and reliable alliance were all similar to emotional support, and social integration was similar to companionship support. There were moderate correlations between attachment, reliable alliance, and guidance with emotional support $(r=.29, p<.001 ; r=.28, p<.001$; and $r=.23, p<.001$, respectively). Social integration was moderately correlated with companionship support $(r=.33, p<.001)$. There was a moderate correlation between social integration and emotional support $(r=.46, p<.001)$, suggesting similarity between these constructs. However, these weak to moderate correlations suggest that the constructs in the PASSS are different than the constructs in the Social Provisions for Exercise Scale.

General Social Support. The Interpersonal Support Evaluation List had the weakest correlation with the overall mean PASSS score $(r=.13, p<.001)$. Even though the correlation between the total PASSS score was low, correlations were still tested between the subscales of the PASSS that were similar to the subscales in the Interpersonal Support Evaluation List. Appraisal support was moderately correlated with emotional support $(r=.26, p<.001)$. Belonging was moderately correlated with companionship support $(r=.27, p<.001)$. Tangible support was moderately correlated with instrumental support $(r=.25, p<.001)$. Correlations between the remaining forms of social support in the PASSS and the forms in the Interpersonal Support Evaluation List were tested. Most of the correlations were low, suggesting that the constructs in the PASSS are different than the constructs in the Interpersonal Support Evaluation List.

Other Social-Psychological Correlates. Correlations between the PASSS and enjoyment of physical activity, exercise dependence, exercise identity, group exercise identity, type of personality, and amount of physical activity were conducted to further explore the construct and discriminant validity of the PASSS (see Table 5 for correlations). Exercise Identity Scale $(r=.51, p<.001)$, the Physical Activity Enjoyment Scale $(r=.41, p<.001)$, and Exercise Dependence Scale $(r=.45, p<.001)$ had the strongest correlations with the overall mean PASSS score. Group Exercise Identity Scale $(r=.37$, $p<.001$ ) had moderate correlations with the total mean PASSS. The Ten-Item Personality Scale is comprised of extraversion, agreeableness, conscientiousness, emotional stability, and openness to experiences. The overall mean PASSS score had weak correlations with extraversion $(r=.15, p<.001)$ and conscientiousness $(r=.17$, $p<.001)$. There were no significant correlations with the overall mean PASSS score and agreeableness, openness to experiences, or emotional stability.

Physical Activity Measures. The final set of analyses centered on correlations with measure of physical activity behavior. The overall mean PASSS score was significantly correlated with the total moderate-to-vigorous physical activity from the International Physical Activity Questionnaire $(r=.31, p<.01)$ and the S-MAQ $(r=.39, p<.01)$, with a significant, though small, negative correlation $(r=-.18, p<.01)$ with sedentary behaviors. Of note, these correlations were significantly stronger than the other measures of social support for physical activity (see Table 6). Examining the subscales of the PASSS, companionship had the strongest correlation, followed by informational and emotional support with the amount of physical activity per week.

\section{Discussion}

This research was designed to develop and test the initial validation and psychometric properties of the multidimensional PASSS 


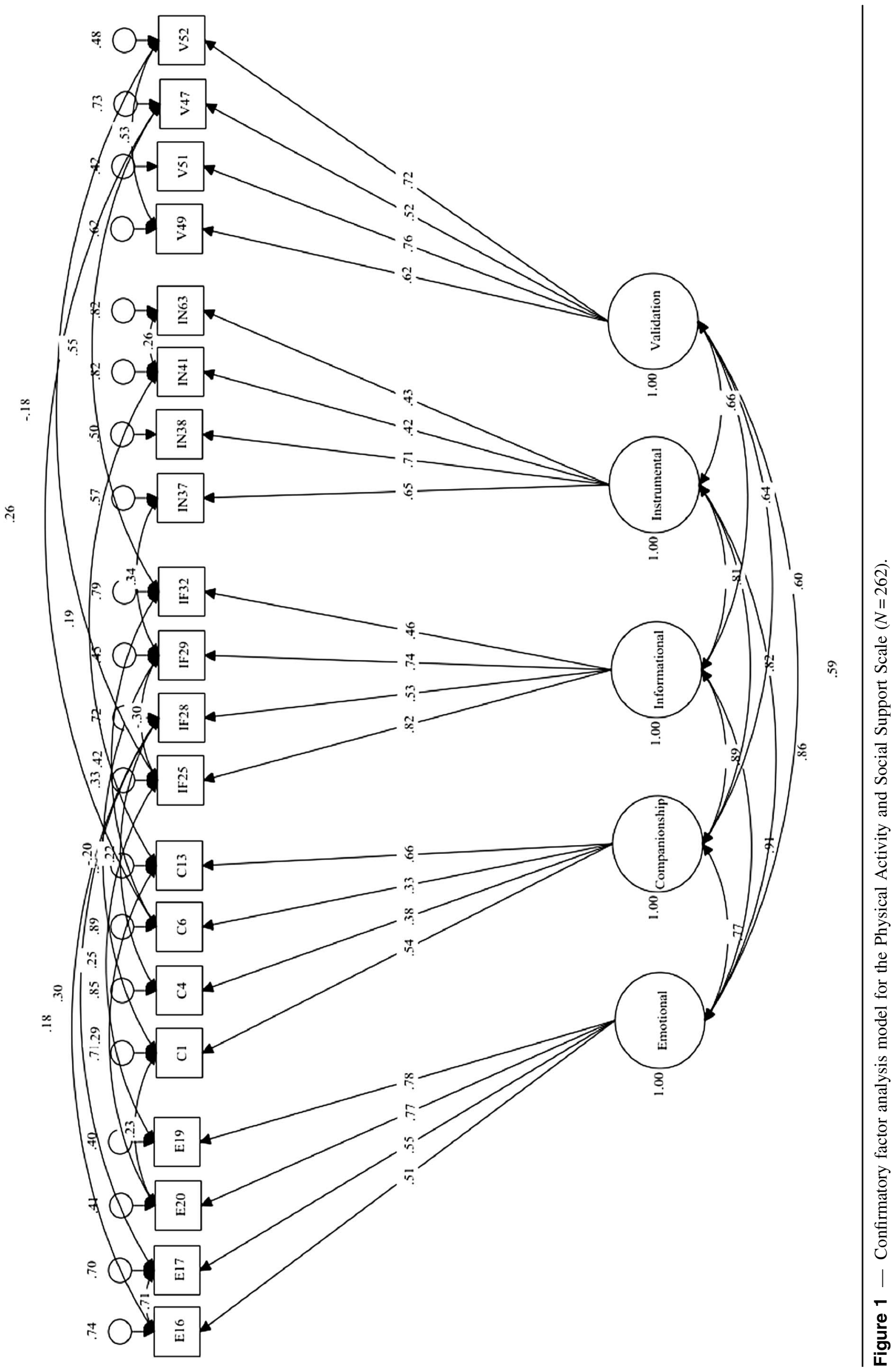


Table 3 Correlations Between PASSS Subscales $(N=506)$

\begin{tabular}{lccccc}
\hline & $\mathbf{1}$ & $\mathbf{2}$ & $\mathbf{3}$ & $\mathbf{4}$ & $\mathbf{5}$ \\
\cline { 2 - 6 } 1. PASSS emotional & 1 & & & \\
2. PASSS companionship & $.61^{*}$ & 1 & & \\
3. PASSS instrumental & $.38^{*}$ & $.35^{*}$ & 1 & & \\
4. PASSS informational & $.50^{*}$ & $.57^{*}$ & $.27^{*}$ & 1 & \\
5. PASSS validation & $.33^{*}$ & $.48^{*}$ & $.24^{*}$ & $.51^{*}$ & 1 \\
\hline
\end{tabular}

Note. PASSS = Physical Activity and Social Support Scale.

$* p<.01$.

Table 4 Convergent and Discriminant Validity for the PASSS: Social Support $(N=506)$

\begin{tabular}{|c|c|c|c|c|c|c|}
\hline & PASSS & $\begin{array}{c}\text { PASSS } \\
\text { emotional }\end{array}$ & $\begin{array}{c}\text { PASSS } \\
\text { companionship }\end{array}$ & $\begin{array}{c}\text { PASSS } \\
\text { instrumental }\end{array}$ & $\begin{array}{c}\text { PASSS } \\
\text { informational }\end{array}$ & $\begin{array}{c}\text { PASSS } \\
\text { validation }\end{array}$ \\
\hline $\begin{array}{l}\text { Social Support for Exercise } \\
\text { Scale (Sallis et al., 1987) }\end{array}$ & $.53 * *$ & $.49 * *$ & $.47 * *$ & $.33 * *$ & $.37 * *$ & $.29 *$ \\
\hline $\begin{array}{l}\text { Social Provisions for Exercise Scale } \\
\text { (Cutrona \& Russell, 1987; adapted to exercise } \\
\text { by McAuley \& Duncan, 1997) }\end{array}$ & $.23 * *$ & $.37 * *$ & $.18 * *$ & $.22 * *$ & .08 & -.02 \\
\hline Attachment & $.16^{* *}$ & $.29 * *$ & $.09 *$ & $.18 * *$ & .03 & -.03 \\
\hline Reliable alliance & $.18 * *$ & $.29 * *$ & $.13 * *$ & $.16^{*}$ & .07 & -.01 \\
\hline Guidance & $.10 *$ & $.23 * *$ & .08 & $.12 * *$ & .00 & -.09 \\
\hline Social integration & $.36 * *$ & $.46 * *$ & $.33 * *$ & $.26 * *$ & $.17 *$ & .09 \\
\hline Worth & $.16^{* *}$ & $.28 * *$ & $.12 * *$ & $.13 * *$ & .08 & -.04 \\
\hline $\begin{array}{l}\text { Interpersonal Support Evaluation } \\
\text { List-12 (Cohen et al., 1985) }\end{array}$ & $.13 * *$ & $.36 * *$ & $.20 * *$ & $.28 * *$ & .08 & .00 \\
\hline Appraisal & $.13 * *$ & $.26^{*}$ & $.09 *$ & $.16^{* *}$ & .00 & -.07 \\
\hline Belonging & $.31 * *$ & $.38 * *$ & $.27 *$ & $.30 * *$ & $.15^{* *}$ & .04 \\
\hline Tangible support & $.19 * *$ & $.26 * *$ & $.14 * *$ & $.25^{*}$ & .04 & .01 \\
\hline
\end{tabular}

Note. PASSS $=$ Physical Activity and Social Support Scale.

$* p<.05 . * * p<.01$

among an active adult population. The PASSS enables social support for physical activity to be conceptualized and measured with five, well-established forms of functional social supportcompanionship, validation, emotional, informational, and instrumental support (Argyle, 1992; Berkman \& Glass, 2000; Cohen et al., 2000b; House, 1981) through a 20-item (four items per form) Likert-type scale. The EFA extraction methods indicated a fivefactor model. Item-reduction methods were used to examine communalities and pattern coefficients, to finalize a five-factor, 20-item scale. CFA was used for the initial validation of the PASSS. The PASSS also indicated acceptable convergent and discriminant validity and test-retest reliability.

The initial CFA model did not provide a good fit to these data. Model fit indices improved the model to an acceptable level once errors among items were allowed to correlate. This is a standard adjustment to building a measurement model as allowing for correlated errors accounts for the systematic rather than random measurement error in item responses. These errors may stem from participant or item characteristics (Aish \& Jöreskog, 1990). Participant characteristics may include a bias such as "yea-saying or naysaying or social desirability" (Aish \& Jöreskog, 1990). There would inherently be overlap of the items within each subscale (companionship, emotional, validation, informational, and instrumental) as the items are tapping into each functional form of social support for physical activity along with the overarching construct of social support. The relationships between subscales are common and often explain correlated errors between items (Aish \& Jorekog, 1990). For example, items that measure companionship support likely carries opportunities for informational and emotional support. In addition, beyond these forms of correlated errors that are common to most measures, the different forms of social support were hypothesized to correlate as one individual would often be expected to provide different forms of support. That is, people who provide companionship support may also provide emotional support. Given these expectations, we followed the advice of Bentler and Chou (1987) who note that forcing large error terms to be uncorrelated is rarely appropriate with real data and that correlating the residuals is appropriate when making modifications to models.

\section{Strengths}

There are a number of strengths to this research. First, the items and resulting subscales are based on the strong, theoretical basis that overcomes the limitations in the existing measures. The PASSS is based in the dominant health and social support buffering hypothesis literature (Cohen et al., 2000b). As such, it builds on a broad, well-supported literature of social support and allows for comparison of physical activity with other health behaviors. Where the existing social support for physical activity scales are based in companionship, emotional, and instrumental support, with only 
Table 5 Convergent and Discriminant Validity for the PASSS: Physical Activity Behaviors $(N=506)$

\begin{tabular}{|c|c|c|c|c|c|c|}
\hline & PASSS & $\begin{array}{l}\text { PASSS } \\
\text { emotional }\end{array}$ & $\begin{array}{c}\text { PASSS } \\
\text { companionship }\end{array}$ & $\begin{array}{c}\text { PASSS } \\
\text { instrumental }\end{array}$ & $\begin{array}{c}\text { PASSS } \\
\text { informational }\end{array}$ & $\begin{array}{l}\text { PASSS } \\
\text { validation }\end{array}$ \\
\hline $\begin{array}{l}\text { Exercise Dependence Scale } \\
\text { (Hausenblas \& Downs, 2002) }\end{array}$ & $.45 * *$ & $.30 * *$ & $.38 * *$ & $.14 *$ & $.43 * *$ & $.43 * *$ \\
\hline $\begin{array}{l}\text { Physical Activity Enjoyment Scale } \\
\text { (Kendzierski \& DeCarlo, 1991) }\end{array}$ & $.41^{* *}$ & $.46^{* *}$ & $.41 * *$ & $.14^{*}$ & $.33 * *$ & $.16^{*}$ \\
\hline $\begin{array}{l}\text { Exercise Identity Scale } \\
\text { (Anderson \& Cychosz, 1994) }\end{array}$ & $.51 * *$ & $.39 * *$ & $.46^{* *}$ & $.17^{*}$ & $.47 * *$ & $.39 * *$ \\
\hline Group Identity Scale (Cameron, 2004) & $.37 * *$ & $.24 * *$ & $.40 * *$ & $.12 * *$ & $.28 * *$ & $.32 * *$ \\
\hline \multicolumn{7}{|l|}{$\begin{array}{l}\text { Ten-Item Personality Scale } \\
\text { (Gosling, Rentfrow, \& Swann, 2003) }\end{array}$} \\
\hline Extraversion & $.15^{* *}$ & $.16^{* *}$ & $.15 * *$ & $.10^{*}$ & .05 & .07 \\
\hline Agreeableness & .07 & $.15^{*}$ & .08 & .01 & .07 & -.07 \\
\hline Conscientiousness & $.17 * *$ & $.18 * *$ & $.20 * *$ & .03 & $.15^{*}$ & .06 \\
\hline Emotional stability & .03 & $.09^{*}$ & .08 & -.03 & .03 & -.07 \\
\hline Openness to experiences & .08 & $.11^{*}$ & .07 & .08 & $.11 *$ & -.06 \\
\hline $\begin{array}{l}\text { International Physical Activity Questionnaire } \\
\text { (MVPA; Craig et al., 2003) }\end{array}$ & $.31 * *$ & $.21 * *$ & $.30 * *$ & $.18 * *$ & $.27 * *$ & $.20 * *$ \\
\hline $\begin{array}{l}\text { International Physical Activity Questionnaire } \\
\text { (sedentary time; Craig et al., 2003) }\end{array}$ & $-.18^{* *}$ & $-.17 * *$ & $-.20 * *$ & $-.16^{* *}$ & -.13 & .00 \\
\hline $\begin{array}{l}\text { Self-report Modifiable Activity Questionnaire } \\
\text { (adapted from Kriska et al., 1990) }\end{array}$ & $.39 * *$ & $.24 * *$ & $.41 * *$ & $.22 * *$ & $.36^{* *}$ & $.21 * *$ \\
\hline
\end{tabular}

Note PASSS $=$ Physical Activity and Social Support Scale; MVPA = moderate to vigorous physical activity.

$* p<.05$. ** $p<.01$.

Table 6 Correlations Between Social Support for Physical Activity Measures and Moderate to Vigorous Physical Activity per Week $(N=506)$

\begin{tabular}{lcc}
\hline & $\begin{array}{c}\text { S-MAQ } \\
\text { MET-min/week }\end{array}$ & $\begin{array}{c}\text { IPAQ } \\
\text { MET-min/week }\end{array}$ \\
\hline Overall PASSS & $.39^{* *}$ & $.31^{* *}$ \\
Emotional & $.24^{* *}$ & $.21^{* *}$ \\
Validation & $.21^{* *}$ & $.20^{* *}$ \\
Informational & $.36^{* *}$ & $.27^{* *}$ \\
Instrumental & $.22^{* *}$ & $.18^{* *}$ \\
Companionship & $.41^{* *}$ & $.30^{* *}$ \\
Overall social provisions & .08 & $.10^{*}$ \\
for exercise & & \\
Guidance & .04 & .06 \\
Attachment & .04 & .06 \\
Social integration & $.13^{* *}$ & $.16^{* *}$ \\
Reliable alliance & .06 & .08 \\
Worth & $.12^{* *}$ & .05 \\
Overall social support & $.24^{* *}$ & $.20^{* *}$ \\
for exercise & & $.11^{*}$ \\
Family & $.10^{*}$ & $.21^{* *}$ \\
Friends & $.28^{* *}$ & \\
\hline
\end{tabular}

Note. $\mathrm{MVPA}=$ moderate to vigorous physical activity; $\mathrm{S}-\mathrm{MAQ}=$ self-report Modifiable Activity Questionnaire; IPAQ = International Physical Activity Questionnaire; MET $=$ metabolic equivalent; PASSS $=$ Physical Activity and Social Support Scale.

$* p<.05$. ** $p<.01$. some consideration for informational support (Chogahara, 1999; Sallis et al., 1987), the PASSS assesses all five hypothesized forms of functional social support as individual subscales. Rather than utilize a narrow source of social support from family and friends (Sallis et al., 1987; Scarapicchia et al., 2017), the PASSS encompasses any and all individuals who are perceived to provide social support. Furthermore, most scale development efforts are overly reliant on samples of young participants that undermine the ability to generalize the findings (Hanel \& Vione, 2016). Our sample included $12 \% 18$ - to 20 -year olds, $38 \% 21$ - to 30 -year olds, $25 \%$ 31 - to 40 -year olds, $10 \% 41$ - to 50 -year olds, $9 \% 51$ - to 60 -year olds, 5\% 61- to 70-year olds, and 1\% 71- to 75-year olds. Finally, the iterative, multimethod approach used to develop the PASSS, the use of a randomly selected split-half samples for the CFA and EFA, along with the range of comparisons for validity and reliability provide confidence in the resulting model.

In addition to the strengths mentioned previously, the PASSS accounted for more than double the amount of variance in physical activity per week (15\%) compared with existing social support for physical activity scales-with strong performance at the individual subscale level: companionship (17\%), emotional (6\%), validation (4\%), informational (13\%), and instrumental $(5 \%)$. By contrast, the Social Support for Exercise Survey accounted for $6 \%$ of variance in weekly physical activity and the Social Provisions for Exercise Scale accounted for 1\%. Not only does this support the potential of the PASSS to make significant contributions to our understanding of social support and physical activity, the pattern of results illustrates the importance and potential of the separate subscales for each of the five, functional forms of social support for physical activity. Future research should explore the pattern of these effects and how they vary across different subgroups and over time. Such data will help 
illustrate the dynamic relationship between social support and physical activity that may guide targeted interventions that are more likely to achieve increased physical activity.

\section{Limitations}

Although the PASSS was developed and validated in separate samples and shows good psychometric properties, it is not without limitations. First, both studies used a cross-sectional design, which only allows a snapshot of social support and physical activity involvement. Social support is dynamic and may fluctuate over time (Oka et al., 1995). For example, forms of social support might be different for those who are in the initiation phase of adopting an active lifestyle versus those who are in a maintenance stage. Second, participants were selected based on some level of activity as we wanted to ensure that the items would be of relevance to each respondent. This resulted in a sample of adults who are highly active $(\mathrm{S}-\mathrm{MAQ}=2,108.43$ [SD = 1,911.85] MET-min/week and International Physical Activity Questionnaire $=4,576.50[S D=3,272.58]$ MET-min/week), well above the physical activity guidelines of $600 \mathrm{MET}-\mathrm{min} /$ week. It is likely that less active individuals will respond differently to these items, and future research should test the psychometric properties of a less active sample. Third, these studies did not capture other factors that might influence individual's physical activity from either life status, for example, recent injury; change in life status (Allender, Hutchinson, \& Foster, 2008); environmental influences (Brownson, Hoehner, Day, Forsyth, \& Sallis, 2009); psychosocial sources such as self-efficacy (McAuley, Szabo, Gothe, \& Olson, 2011); and motivation (McNeill et al., 2006). Finally, there is a lack of diversity within the sample, which was majority white, educated, and female. Social support varies in form as a function of culture (Kim, Sherman, \& Taylor, 2008). Furthermore, the data for this study were collected online such that only those with access to and comfort with a computer, tablet, or smartphone could complete the survey. Future research should work to validate the PASSS in a more diverse sample of participants.

\section{Conclusions}

The development and validation of the PASSS makes a significant contribution to the physical activity literature as it broadens our understanding of social support for physical activity. The most widely used scale assesses companionship, emotional, and instrumental support, often as a single score, which has limited the complexity of questions that could be asked about social support and physical activity. The PASSS is based in five forms of functional social support for physical activity-companionship, emotional, informational, instrumental, and validation, which will aid in the creation of informative and comprehensive interventions to increase adherence to physical activity through a target change in social support. Longitudinal work is needed to understand the dynamic range of these forms of social support over time. Further psychometric and validation testing of the PASSS are needed, especially among more diverse populations in order to extend its utility. However, the PASSS provides a platform to undertake this research and significantly advance our understanding of how forms of social support are associated with physical activity behaviors.

\section{Acknowledgment}

The authors would like to thank Drs. Alexandra Loukas, Harold W. Kohl, and Justin Moore for their contribution to the development of this paper.

\section{References}

2018 Physical Activity Guidelines Advisory Committee. (2018). 2018 Physical Activity Guidelines Advisory Committee scientific report. Washington, DC: Department of Health and Human Services.

Aish, A.-M., \& Jöreskog, K.G. (1990). A panel model for political efficacy and responsiveness: An application of LISREL 7 with weighted least squares. Quality \& Quantity, 24(4), 405-426. doi:10.1007/ BF00152013

Allender, S., Hutchinson, L., \& Foster, C. (2008). Life-change events and participation in physical activity: A systematic review. Health Promotion International, 23(2), 160-172. PubMed ID: 18364364 doi:10.1093/heapro/dan012

Anderson, D.F., \& Cychosz, C.M. (1994). Development of an exercise identity scale. Perceptual and Motor Skills, 78(3 Pt. 1), 747-751.

Anderson, D.F., Cychosz, C.M., \& Franke, W.D. (2001). Preliminary Exercise Identity Scale (EIS) norms for three adult samples. Journal of Sport Behavior, 24(1), 1.

Argyle, M. (1992). Benefits produced by supportive social relationships. In H.O.F. Veiel\& U. Baumann (Eds.), The series in clinical and community psychology. The meaning and measurement of social support (pp. 13-32). Washington, DC: Hemisphere Publishing.

Barber, F.D. (2012). Social support and physical activity engagement by cancer survivors. Clinical Journal of Oncology Nursing, 16(3), E84-E98. PubMed ID: 22641333 doi:10.1188/12.CJON.E84-E98

Bauman, A.E., Reis, R.S., Sallis, J.F., Wells, J.C., Loos, R.J., \& Martin, B.W. (2012). Correlates of physical activity: Why are some people physically active and others not? Lancet, 380(9838), 258-271. doi:10.1016/S0140-6736(12)60735-1

Bentler, P.M. (1990). Comparative fit indexes in structural models. Psychological Bulletin, 107(2), 238-246. PubMed ID: 2320703 doi:10.1037/0033-2909.107.2.238

Bentler, P.M., \& Chou, C.-P. (1987). Practical issues in structural modeling. Sociological Methods \& Research, 16(1), 78-117. doi:10.1177/ 0049124187016001004

Berkman, L.F., \& Glass, T. (2000). Social integration, social networks, social support, and health. Social Epidemiology, 1, 137-173.

Brown, T.A. (2006). Confirmatory factor analysis for applied research (1st ed.). New York, NY: The Guilford Press.

Browne, M.W., \& Cudeck, R. (1992). Alternative ways of assessing model fit. Sociological Methods \& Research, 21(2), 230-258. doi:10.1177/ 0049124192021002005

Brownson, R.C., Hoehner, C.M., Day, K., Forsyth, A., \& Sallis, J.F. (2009). Measuring the built environment for physical activity: State of the science. American Journal of Preventive Medicine, 36(4 Suppl.), S99-S123.e12. PubMed ID: 19285216 doi:10.1016/ j.amepre.2009.01.005

Cameron, J.E. (2004). A three-factor model of social identity. Self and Identity, 3(3), 239-262.

Byrne, B.M. (2011). Structural equation modeling with Mplus: Basic concepts, applications, and programming (1st ed.). New York, NY: Routledge.

Carron, A.V., Hausenblas, H.A., \& Mack, D. (1996). Social influence and exercise: A meta-analysis. Journal of Sport \& Exercise Psychology, 18(1), 1-16. doi:10.1123/jsep.18.1.1

Centers for Disease Control and Prevention. (2018). Benefits of physical activity. Atlanta: Author. Retrieved from https://www.cdc.gov/ physicalactivity/basics/pa-health/index.htm

Chogahara, M. (1999). A multidimensional scale for assessing positive and negative social influences on physical activity in older adults. Journals of Gerontology, Series B: Psychological Sciences and Social Sciences, 54B(6), S356-S367. doi:10.1093/geronb/54B.6.S356 
Cohen, S., \& McKay, G. (1984). Social support, stress and the buffering hypothesis: A theoretical analysis. In A. Baum, S.E. Taylor, \& J.E. Singer (Eds.), Handbook of psychology and health (Vol. 4, pp. 253267). Hillsdale, NJ: Erlbaum.

Cohen, S., Mermelstein, R., Kamarck, T., \& Hoberman, H.M. (1985). Measuring the functional components of social support. In I.G. Sarason \& B. Sarason (Eds.), Social support: Theory, research and applications (pp. 73-94). The Hague, the Netherlands: MartinusNijhoff.

Cohen, S., Underwood, L.G., \& Gottlieb, B.H. (2000a). Social support measurement and intervention: A guide for health and social scientists. New York: Oxford University Press.

Cohen, S., Underwood, L.G., \& Gottlieb, B.H. (2000b). Measuring and intervening in social support. In S. Cohen, L. Underwood, \& B. Gottlieb (Eds.), Social relationships and health (pp. 3-25). New York, NY: Oxford University Press.

Cohen, S., \& Wills, T.A. (1985). Stress, social support, and the buffering hypothesis. Psychological Bulletin, 98(2), 310-357. PubMed ID: 3901065 doi:10.1037/0033-2909.98.2.310

Corbin, J., \& Strauss, A. (2007). Basics of qualitative research: Techniques and procedures for developing grounded theory (3rd ed.). Los Angeles, CA: SAGE Publications, Inc.

Courneya, K.S., \& McAuley, E. (1995). Reliability and discriminant validity of subjective norm, social support, and cohesion in an exercise setting. Journal of Sport \& Exercise Psychology, 17(3), 325-337. doi:10.1123/jsep.17.3.325

Courneya, K.S., Plotnikoff, R.C., Hotz, S.B., \& Birkett, N.J. (2000). Social support and the theory of planned behavior in the exercise domain. American Journal of Health Behavior, 24(4), 300-308. doi:10.5993/ AJHB.24.4.6

Cousins, S.O. (1995). Social support for exercise among elderly women in Canada. Health Promotion International, 10(4), 273-282. doi:10. 1093/heapro/10.4.273

Craig, C.L., Marshall, A.L., Sjöström, M., Bauman, A.E., Booth, M.L., Ainsworth, B.E., ... Oja, P. (2003). International Physical Activity Questionnaire: 12-country reliability and validity. Medicine \& Science in Sports \& Exercise, 35(8), 1381-1395. PubMed ID: 12900694 doi:10.1249/01.MSS.0000078924.61453.FB

Cutrona, C.E., \& Russell, D.W. (1987). The provisions of social relationships and adaptation to stress. Advances in Personal Relationships, 1, 37-67.

Duncan, T.E., \& McAuley, E. (1993). Social support and efficacy cognitions in exercise adherence: A latent growth curve analysis. Journal of Behavioral Medicine, 16(2), 199-218. PubMed ID: 8315646 doi:10. 1007/BF00844893

Duncan, T.E., \& Stoolmiller, M. (1993). Modeling social and psychological determinants of exercise behaviors via structural equation systems. Research Quarterly for Exercise and Sport, 64(1), 1-16. PubMed ID: 8451525 doi:10.1080/02701367.1993.10608773

Durand, C.P., Oluyomi, A.O., Gabriel, K.P., Salvo, D., Sener, I.N., Hoelscher, D.M., ... Kohl, H.W. III. (2016). The effect of light rail transit on physical activity: Design and methods of the TravelRelated Activity in Neighborhoods Study. Frontiers in Public Health, 4, 103. PubMed ID: 27376051 doi:10.3389/fpubh.2016. 00103

Ehrhart, M.G., Ehrhart, K.H., Roesch, S.C., Chung-Herrera, B.G., Nadler, K., \& Bradshaw, K. (2009). Testing the latent factor structure and construct validity of the Ten-Item Personality Inventory. Personality and Individual Differences, 47(8), 900-905. doi:10.1016/j. paid.2009.07.012

Eyler, A.A., Brownson, R.C., Donatelle, R.J., King, A.C., Brown, D., \& Sallis, J.F. (1999). Physical activity social support and middle- and older-aged minority women: Results from a US survey. Social Science \& Medicine, 49(6), 781-789. PubMed ID: 10459889 doi:10.1016/S0277-9536(99)00137-9

Fabrigar, L.R., \& Wegener, D.T. (2011). Exploratory factor analysis. New York: Oxford University Press.

Furnham, A. (2008). Relationship among four Big Five measures of different length. Psychological Reports, 102(1), 312-316. PubMed ID: 18481692 doi:10.2466/pr0.102.1.312-316

Gabriel, K.P., McClain, J.J., Schmid, K.K., Storti, K.L., \& Ainsworth, B.E. (2011). Reliability and convergent validity of the past-week Modifiable Activity Questionnaire. Public Health Nutrition, 14(3), 435-442. doi:10.1017/S1368980010002612

Gillett, P.A. (1988). Self-reported factors influencing exercise adherence in overweight women. Nursing Research, 37(1), 25-29. PubMed ID: 3340574 doi:10.1097/00006199-198801000-00006

Gosling, S.D., Rentfrow, P.J., \& Swann, W.B. (2003). A very brief measure of the Big-Five personality domains. Journal of Research in Personality, 37(6), 504-528.

Gottlieb, B.H., \& Bergen, A.E. (2010). Social support concepts and measures. Journal of Psychosomatic Research, 69(5), 511-520. PubMed ID: 20955871 doi:10.1016/j.jpsychores.2009.10.001

Hanel, P.H.P., \& Vione, K.C. (2016). Do student samples provide an accurate estimate of the general public? PLoS ONE, 11(12), e0168354. PubMed ID: 28002494 doi:10.1371/journal.pone.0168354

Hausenblas, H.A., \& Downs, D.S. (2002). How much is too much? The development and validation of the Exercise Dependence Scale. Psychology \& Health, 17(4), 387-404.

HealthyPeople 2020. (2014). Physical activity healthy people, 2020. Retrieved from https://www.healthypeople.gov/2020/topics-objectives/ topic/physical-activity/national-snapshot

House, J.S. (1981). Work stress and social support. Reading, MA: Addison-Wesley.

Hu, L., \& Bentler, P.M. (1999). Cutoff criteria for fit indexes in covariance structure analysis: Conventional criteria versus new alternatives. Structural Equation Modeling, 6(1), 1-55. doi:10.1080/10705519909540118

Jöreskog, K.G., \& Sörbom, D. (1993). LISREL 8: Structural equation modeling with the SIMPLIS command language. Chicago, IL: Scientific Software International.

Kendzierski, D., \& DeCarlo, K.J. (1991). Physical Activity Enjoyment Scale: Two validation studies. Journal of Sport \& Exercise Psychology, 13(1), 50-64. doi: 10.1123/jsep.13.1.50

Kenny, D.A. (2015). Mediation. Retrieved from http://davidakenny.net/ $\mathrm{cm} /$ mediate.htm

Kim, H.S., Sherman, D.K., \& Taylor, S.E. (2008). Culture and social support. American Psychologist, 63(6), 518-526. PubMed ID: 18793039 doi:10.1037/0003-066X

Knell, G., Durand, C.P., Shuval, K., Kohl, H.W., III, Salvo, D., Sener, I., \& Gabriel, K.P. (2017). Transit use and physical activity: Findings from the Houston Travel-Related Activity in Neighborhoods (TRAIN) Study. Preventive Medicine Reports, 9, 55-61. PubMed ID: 29340271 doi:10.1016/j.pmedr.2017.12.012

Koo, T.K., \& Li, M.Y. (2016). A guideline of selecting and reporting intraclass correlation coefficients for reliability research. Journal of Chiropractic Medicine, 15(2), 155-163. PubMed ID: 27330520 doi:10.1016/j.jcm.2016.02.012

Kriska, A.M., Knowler, W.C., LaPorte, R.E., Drash, A.L., Wing, R.R., Blair, S.N., .. Kuller, L.H. (1990). Development of questionnaire to examine relationship of physical activity and diabetes in Pima Indians. Diabetes Care, 13(4), 401-411. PubMed ID: 2318100 doi:10.2337/diacare.13.4.401

Loehlin, J.C. (1998). Latent variable models: An introduction to factor, path, and structural analysis. Mahwah, NJ: Lawrence Erlbaum. 
MacCallum, R.C., Browne, M.W., \& Sugawara, H.M. (1996). Power analysis and determination of sample size for covariance structure modeling. Psychological Methods, 1(2), 130-149. doi:10.1037/1082989X.1.2.130

McAuley, E., Szabo, A., Gothe, N., \& Olson, E.A. (2011). Self-efficacy: Implications for physical activity, function, and functional limitations in older adults. American Journal of Lifestyle Medicine, 5(4), 361369. doi:10.1177/1559827610392704

McCrae, R.R., Kurtz, J.E., Yamagata, S., \& Terracciano, A. (2011). Internal consistency, retest reliability, and their implications for personality scale validity. Personality and Social Psychology Review, 15(1), 28-50. PubMed ID: 31142181 doi:10.1177/ 1088868310366253

McNeill, L.H., Kreuter, M.W., \& Subramanian, S.V. (2006). Social environment and physical activity: A review of concepts and evidence. Social Science \& Medicine, 63(4), 1011-1022. PubMed ID: 16650513 doi:10.1016/j.socscimed.2006.03.012

Momenan, A.A., Delshad, M., Sarbazi, N., Rezaei Ghaleh, N., Ghanbarian, A., \& Azizi, F. (2012). Reliability and validity of the Modifiable Activity Questionnaire (MAQ) in an Iranian urban adult population. Archives of Iranian Medicine, 15(5), 279-282. PubMed ID: 22519376

Muthén, L.K., \& Muthén, B.O. (2002). How to use a Monte Carlo study to decide on sample size and determine power. Structural Equation Modeling, 9(4), 599-620. doi:10.1207/S15328007SEM0904_8

Muthén, L.K., \& Muthén, B.O. (2008). Mplus (version 5.1). Los Angeles, CA: Muthén \& Muthén.

Nahm, A., Rao, S.S., Solis-Galvan, L., \& Ragu-Nathan, T.S. (2002). The Q-sort method: Assessing reliability and construct validity of questionnaire items at a pre-testing stage. Journal of Modern Applied Statistical Methods, 1(1). doi:10.22237/jmasm/1020255360

Oka, R.K., King, A.C., \& Young, D.R. (1995). Sources of social support as predictors of exercise adherence in women and men ages 50 to 65 years. Women's Health, 1(2), 161-175. PubMed ID: 31174227

Oman, R.E., \& Duncan, T.E. (1995). Women and exercise: An investigation of the roles of social support, self-efficacy, and hardiness. Medicine, Exercise, Nutrition and Health, 4(5), 306-315.

Pituch, K.A., \& Stevens, J.P. (2015). Applied multivariate statistics for the social sciences: Analyses with SAS and IBM's SPSS (6th ed.). New York, NY: Routledge.

Rhodes, R.E., \& Smith, N.E.I. (2006). Personality correlates of physical activity: A review and meta-analysis. British Journal of Sports Medicine, 40(12), 958-965. PubMed ID: 17124108 doi:10.1136/ bjsm.2006.028860

Sallis, J.F., Calfas, K.J., Alcaraz, J.E., Gehrman, C., \& Johnson, M.F. (1999). Potential mediators of change in a physical activity promotion course for university students: Project GRAD. Annals of Behavioral Medicine, 21(2), 149-158. doi:10.1007/BF02908296

Sallis, J.F., Grossman, R.M., Pinski, R.B., Patterson, T.L., \& Nader, P.R. (1987). The development of scales to measure social support for diet and exercise behaviors. Preventive Medicine, 16(6), 825-836. PubMed ID: 3432232 doi:10.1016/0091-7435(87)90022-3

Sallis, J.F., Hovell, M.F., Hofstetter, C.R., \& Barrington, E. (1992). Explanation of vigorous physical activity during two years using social learning variables. Social Science \& Medicine, 34(1), 25-32. PubMed ID: 1738853 doi:10.1016/0277-9536(92)90063-V
Satorra, A., \& Bentler, P.M. (1988). Scaling corrections for statistics in covariance structure analysis (UCLA Statistics Series \#2). Los Angeles: University of California.

Scarapicchia, T.M.F., Amireault, S., Faulkner, G., \& Sabiston, C.M. (2017). Social support and physical activity participation among healthy adults: A systematic review of prospective studies. International Review of Sport and Exercise Psychology, 10(1), 50-83. doi:10.1080/1750984X.2016.1183222

Sherbourne, C.D., \& Stewart, A.L. (1991). The MOS social support survey. Social Science \& Medicine, 32(6), 705-714. PubMed ID: 2035047 doi:10.1016/0277-9536(91)90150-B

Sherwood, N.E., \& Jeffery, R.W. (2000). The behavioral determinants of exercise: Implications for physical activity interventions. Annual Review of Nutrition, 20, 21-44. PubMed ID: 31150593 doi:10. 1146/annurev.nutr.20.1.21

Statistical Package for the Social Sciences. (2017). IBM SPSS statistics for windows (version 25). Armonk, NY: IBM Corp.

Steiger, J.H. (1990). Structural model evaluation and modification: An interval estimation approach. Multivariate Behavioral Research, 25(2), 173-180. PubMed ID: 26794479 doi:10.1207/ s15327906mbr2502_4

Stephenson, W. (1953). The study of behavior: Q-technique and its methodology. Chicago, IL: University of Chicago Press.

Strachan, S.M., Shields, C.A., Glassford, A., \& Beatty, J. (2012). Role and group identity and adjustment to the possibility of running group disbandmen. Psychology of Sport and Exercise, 13(4), 436-443. doi:10.1016/j.psychsport.2012.01.007

Stryker, S. (1980). Symbolic interactionism: A social structural version. Menlo Park, CA: Benjamin-Cummings.

Tay, L., Tan, K., Diener, E., \& Gonzalez, E. (2013). Social relations, health behaviors, and health outcomes: A survey and synthesis. Applied Psychology: Health and Well-Being, 5(1), 28-78. doi:10.1111/aphw. 12000

Terry, D.J., \& Hogg, M.A. (1996). Group norms and the attitudebehavior relationship: A role for group identification. Personality and Social Psychology Bulletin, 22(8), 776-793. doi:10.1177/ 0146167296228002

Thoits, P.A. (1986). Social support as coping assistance. Journal of Consulting and Clinical Psychology, 54(4), 416-423.

Trost, S.G., Owen, N., Bauman, A.E., Sallis, J.F., \& Brown, W. (2002). Correlates of adults' participation in physical activity: Review and update. Medicine \& Science in Sports \& Exercise, 34(12), 1996-2001. PubMed ID: 12471307 doi:10.1097/00005768-200212000-00020

Tucker, L.R., \& Lewis, C. (1973). A reliability coefficient for maximum likelihood factor analysis. Psychometrika, 38(1), 1-10. doi:10.1007/ BF02291170

Weiss, R.S. (1974). The provisions of social relationships. In Z. Rubin (Ed.), Doing unto others (pp. 17-26). Englewood Cliffs, NJ: Prentice-Hall.

Wendel-Vos, W., Droomers, M., Kremers, S., Brug, J., \& van Lenthe, F. (2007). Potential environmental determinants of physical activity in adults: A systematic review. Obesity Reviews, 8(5), 425-440. doi:10. 1111/j.1467-789X.2007.00370.x

White, K.M., Terry, D.J., \& Hogg, M.A. (1994). Safer sex behavior: The role of attitudes, norms, and control factors. Journal of Applied Social Psychology, 24(24), 2164-2192. doi:10.1111/j.1559-1816.1994. tb02378.x 


\section{Appendix: The Physical Activity and Social Support Scale (PASSS)}

\section{Instructions}

This questionnaire pertains to the physical activity/activities that you do-from things like moderately paced walking to different types of exercise (gym, running, cycling) to various activities (hiking, climbing, dancing). Support for these activities can come from many different sources, including: friends and family, live or virtual groups, online discussions, and even internet or magazine searches. Keep these in mind when answering the following questions. Please indicate to what extent each of the following items is associated with the physical activity/activities that you engage in: $1=$ never true, $4=$ sometimes true, $7=$ always true, $\mathrm{n} / \mathrm{a}=$ not applicable (score this as 0 )

1. I have someone who can provide reassurance in the activity/ activities.

2. There is someone that provides me with positive feedback in the activity/activities.

3. There is someone who understands my problems/worries about the activity/activities.

4. I have someone with whom I can relate to in the activity/ activities.

5. I set expectations based on the performance of others in the activity/activities.

6. I want to know competition results (i.e., race results), times, duration, weights, or actions of others in the activity/activities.

7. I compare myself to others in the activity/activities.

8. I use social media to find other people's performance in the activity/activities to compare to my own.

9. I read articles about the activity/activities.

10. I seek out information from others to get better at the activity/ activities.
11. I talk to people for assistance or to improve technique in the activity/activities.

12. I attend clinics, classes, and workshops to learn about the activity/activities.

13. I am part of a core group of people who do the activity/ activities.

14. When not engaging in the activity/activities, I still spend time with people that I met while in the activity/activities.

15. I feel a sense of belonging to a group that also does the activity/activities I do.

16. I can find someone to do the activity/activities with, even outside of my friends.

17. I can get help traveling if needed to perform the activity/ activities.

18. I have someone that could loan or give me something to help carry out the activity/activities I do.

19. I have someone who would watch my child(ren) or pets if needed for me to engage in the activity/activities.

20. I can find someone to help on a short notice so that I can engage in the activity/activities.

\section{Forms of Social Support and Corresponding Items}

- Emotional support: \# 1-4

- Informational support: \# 9-12

- Instrumental support: \# 17-20

- Validation support: \# 5-8

- Companionship support: \# 13-16 